\title{
Characterization of a Component in Chick Ciliary Ganglia that Cross- reacts with Monoclonal Antibodies to Muscle and Electric Organ Acetylcholine Receptor ${ }^{1}$
}

\author{
MARTIN A. SMITH, JES STOLLBERG, JON M. LINDSTROM, ${ }^{2}$ AND DARWIN K. BERG ${ }^{3}$ \\ Department of Biology, University of California, San Diego, La Jolla, California 92093
}

\begin{abstract}
Chick ciliary ganglion neurons have previously been shown to contain a component that shares an antigenic determinant with the "main immunogenic region" of the $\alpha$-subunit in nicotinic acetylcholine receptor from skeletal muscle and electric organ. Ultrastructural studies of antibody binding in the ganglion have shown that the cross-reacting antigen exposed on the surface of the neurons is located predominantly in synaptic membrane. Here we show that the neuronal antigen can be identified in detergent extracts of ciliary and sympathetic ganglia, but not in extracts of heart, liver, spinal cord, retina, or dorsal root ganglia. In the ciliary ganglion the component is present as an integral membrane constituent, and, when detergent solubilized, it sediments as a $10 \mathrm{~S}$ species and binds to concanavalin $A$. The component is distinct from the $\alpha$-bungarotoxin-binding site on the neurons since toxin-binding sites and antibody-binding sites can be precipitated separately in ganglion extracts. The component reaches peak levels per ganglionic protein between embryonic days 8 and 12. These are some of the properties expected for the nicotinic acetylcholine receptor on ciliary ganglion neurons.
\end{abstract}

Although many populations of central and peripheral vertebrate neurons have nicotinic acetylcholine receptors (AChRs), little progress has been made in characterizing the neuronal receptor. This has been due largely to the lack of suitable probes. $\alpha$-Bungarotoxin $(\alpha$-BGT) has been very useful for studying the muscle and electric organ $A C h R$, but its applicability to the neuronal reccptor remains controversial. Many neurons with AChRs also have $\alpha$-BGT-binding sites, and in some instances $\alpha$-BGT has been reported to block receptor function on the neurons (Marshall, 1981; Oswald and Freeman, 1981; Syapin et al., 1982) as it does in muscle and electric

Received January 2, 1985; Revised February 21, 1985;

Accepted February 21, 1985

\footnotetext{
1 We thank Drs. Stanley Halvorsen and Diane O'Dowd for comments on the manuscript, and Dr. Susan Hochschwender for purifying Ab 35. We also thank Dannielle Pellegrin and John Cooper for expert technical assistance. Support was provided by the National Institutes of Health (Grants NS 12601 and NS 11323), the Muscular Dystrophy Association, the American Heart Association with funds contributed in part by the California Heart Association, the Los Anyeles and California Chapters of the Myasthenia Gravis Foundation, and the Alexander S. Onassis Charitable Foundation. M. A. S. is a Muscular Dystrophy Postdoctoral Fellow.

${ }^{2}$ Present address: The Salk Institute, P. O. Box, 85800, San Diego, CA 92138 .

${ }^{3}$ To whom correspondence shall be addressed.
}

organ. In other instances $\alpha$-BGT has becn found to have no effect on neuronal AChR function (Nurse and O'Lague, 1975; Duggan et a!., 1976; Ko et al., 1976; Brown and Fumagalli, 1977; Bursztajn and Gershon, 1977; Patrick and Stallcup, 1977a; Carbonetto et al., 1978; Kouvelas et al., 1978; Ascher et al., 1979; Betz, 1981).

Mono- and polyclonal antibodies have been used to examine the relationship between toxin-binding sites and AChRs on neurons, and to detect structural homologies between the neuronal toxin sites and muscle and electric organ AChRs. Antisera prepared against purified Torpedo AChR show partial cross-reactivity against the toxin-binding component in rat brain (Block and Billiar, 1979; Wonnacott et al., 1982; Mills and Wonnacott, 1984) and in chick retina (Betz, 1981). Similarly, partial cross-reactivity was obtained both with an antiserum raised against $A C h R$ puritied from denervated cat muscle and with a monoclonal antibody (mAb) against AChR from denervated chick muscle when tested against the toxin-binding component from chick brain (Norman et al., 1982; Mehraban et al., 1984).

Immunological approaches have also revealed AChR-like antigens on neurons that are distinct from the component that binds $\alpha$-BGT. An antiserum raised against purified $\mathrm{AChR}$ from Electrophorus electric organ blocked AChR function on the pheochromocytoma cell line $\mathrm{PC} 12$ but did not recognize the toxin-binding component on the cells (Patrick and Stallcup, 1977b). mAbs specific for each of the four subunits of Torpedo AChR cross-react with determinants in the lateral spiriform nucleus in chick brain, although $\alpha$-BGT-binding sites in chick brain appear to be excluded from this region (Swanson et al., 1983). These studies indicate that, although the neuronal toxinbinding component has structural similarities to the muscle AChR and may have related funclions, it is premature to equate it with the neuronal AChR.

The chick ciliary ganglion is an interesting system for studying neuronal AChRs. Chemical transmission through the ganglion is mediated by AChRs on both populations of ganglionic neurons, choroid and ciliary (Martin and Pilar, 1963a, b; Landmesser and Pilar, 1978). The neurons also have high affinity $\alpha$-BGT-binding sites, but saturation of the sites with $\alpha$-BGT does not alter AChR function (Ravdin and Berg, 1979; Chiappinelli et al., 1981; Ravdin et al., 1981). The number of toxin sites on the neurons in cell culture is regulated independently from the levels of acetylcholine (ACh) sensitivity, suggesting that functional receptors do not correspond to toxin sites in this case (Smith et al., 1983). A similar conclusion was reached from regulatory studies on PC12 cells in culture (Mitsuka and Hatanaka, 1983). Moreover, ultrastructural studies on the chick ciliary ganglion indicatc that the toxin sites are concentrated on the membrane in the vicinity of synapses but are absent from the postsynaptic membrane itself (Jacob and Berg, 1983). These results indicate that $\alpha$-BGT-binding sites on chick ciliary ganglion neurons are unlikely to represent functional, synaptic AChRs on the cells.

Recent ultrastructural studies have shown that mAbs directed 
against a determinant in the "main immunogenic region" (MIR) of the AChR $\alpha$-subunit from muscle and electric organ cross-react with a determinant on chick ciliary ganglion neurons. In contrast to the distribution of toxin-binding sites on the neurons, the MIR-like determinant was found to have a predominantly synaptic location (Jacob et al., 1984). In the present study we have examined some of the biochemical properties of the neuronal component for comparison with known properties of muscle and neuronal AChRs. A preliminary account of this work has appeared (Smith et al., 1984).

\section{Materials and Methods}

Monoclonal antibodies. Hybridoma cell lines were obtained by fusing myeloma cell lines with spleen cells from rats immunized with purified AChR protein. Anti-MIR mAbs 6, 35, and 203 were raised against receptors from Torpedo (Tzartos and Lindstrom, 1980) and Electrophorus electric organ (Tzartos et al., 1981), and human skeletal muscle (Tzartos et al., 1983), respectively. mAb 43 was raised against $A C h R$ from Electrophorus electric organ but does not recognize the MIR (Tzartos et al., 1981). Stocks were prepared by ammonium sulfate precipitation of hybridoma culture media. mAb 35 was purified further by chromatography on DEAE Affigel Blue ( $S$. Hochschwender, unpublished procedure) and was radioiodinated by a modified chloramine T method as previously described for $\alpha$-BGT (Lindstrom et al., 1981) to produce ${ }^{125}$-mAb 35 with initial specific activities of 2 to $3 \times$ $10^{18} \mathrm{cpm} / \mathrm{mol}{ }^{125} \mathrm{I}-\mathrm{mAb} 35$ was stored at $40^{\circ} \mathrm{C}$ in phosphate-buffered saline containing $0.1 \%$ sodium azide and $10 \mathrm{mg} / \mathrm{ml}$ of bovine scrum albumin (BSA) Immediately before use, aliquots of the labeled antibody were passed through a small DEAE cellulose column to remove material that adsorbed to the resin, thereby reducing backgrounds obtained subsequently in the anlibody-binding assay described below.

Tissue extracts and membrane fractions. Tissue samples were dissected from 16- to 18-day White Leghorn chick embryos (unless otherwise indicated) and were stored on ice in $11 \mathrm{~mm}$ phosphate buffer ( $\mathrm{pH} \mathrm{7.3)} \mathrm{containing} 123$ $\mathrm{mM} \mathrm{NaCl}, 5.4 \mathrm{mM} \mathrm{KCl}, 0.9 \mathrm{mM} \mathrm{CaCl}_{2}$, and $0.4 \mathrm{mM} \mathrm{MgSO}_{4}$. Samples were trimmed free of connective tissue and were homogenized at $4^{\circ} \mathrm{C}$ by hand in $10 \mathrm{~mm} \mathrm{NaPO}_{4}, \mathrm{pH} 7.4$, containing $50 \mathrm{~mm} \mathrm{NaCl}$, and $0.5 \%$ Triton $\mathrm{X}-100$ (homogenization buffer, $\mathrm{HB}$ ), together with a mixture of protease inhibitors consisting of $5 \mathrm{~mm}$ EDTA, $5 \mathrm{~mm}$ EGTA, $5 \mathrm{~mm}$ phenylmethylsulfonyl fluoride, $10 \mu \mathrm{g} / \mathrm{ml}$ of leupeptin, and $10 \mu \mathrm{g} / \mathrm{ml}$ of pepstatin A. Particulate debris was removed by centrifugation for $1 \mathrm{~min}$ in an Eppendorf microfuge at 15,600 $\times$ $g$, and the supernatant fraction was used in binding studies.

To determine the proportion of mAb-binding sites associated with ciliary ganglion membranes, membrane fragments were prepared by homogenizing ganglia in $10 \mathrm{mM} \mathrm{NaPO}_{4}, \mathrm{pH} 7.4$, containing either $50 \mathrm{mM}$ or $1 \mathrm{M} \mathrm{NaCl}$, and collecting the fragments by centrifugation at $26,000 \times g$ for $40 \mathrm{~min}$ at $4^{\circ} \mathrm{C}$. The membrane fragments were then homogenized in $\mathrm{HB}$ and treated as described above to prepare a detergent extract. For comparison, "100\%" control values were determined by combining the particulate and supernatant fractions from the first centrifugation, adding Triton $X-100$ to generate $\mathrm{HB}$, recentrifuging the mixture to remove insoluble material, and assaying the resulting supernatant fraction for mAb 35 -binding sites.

$m A b 35$ binding. ${ }^{125}$-mAb 35 binding to antigen in detergent extracts was measured by using small DEAE cellulose columns to separate antigenantibody complex (which adsorbed to the resin) from free antibody (which passed through the column). Unless otherwise indicated, reaction mixtures contained $5 \mathrm{nM}{ }^{125} \mathrm{I}-\mathrm{mAb} 35$, normal rat serum (1:100 dilution), and the equivalent of one to two ganglia $(\sim 10 \mu \mathrm{g}$ of protein) in $0.020 \mathrm{ml}$ of HB. The reactions were incubated for $1 \mathrm{hr}$ at room temperature, diluted with $0.20 \mathrm{ml}$ of $\mathrm{HB}$, and chromatographed over 0.05-ml DEAE cellulose columns previously equilibrated with $\mathrm{HB}$. Alternatively, triple-size reactions were carried out $(0.060 \mathrm{ml}$ with three to six ganglion equivalents), diluted with $0.60 \mathrm{ml}$ of $\mathrm{HB}$, divided into three equal aliquots, and chromatographed on separate columns. After rinsing with $2 \mathrm{ml}$ of $\mathrm{HB}$, the columns were gamma counted for radioactivity. Nonspecific binding was routinely determined by including a 30 - to 50-fold excess of unlabeled mAb 35 in the reaction mixture and subtracting it from total binding to yield specific binding. Specific binding determined in this way represented greater than $80 \%$ of the total radioactivity retained by the columns in the standard assay. The efficiency of the assay was determined by binding ${ }^{125} \mathrm{I}$-mAb 35 to intact ciliary ganglion neurons grown in cell culture. After washing the cultures to remove free antibody, detergent extracts of the cells were prepared and analyzed to determinc the proportion of antigen-antibody complex retained by the column assay. These experiments indicated a retention efficiency of $64 \%$ (J. Stollberg, unpublished observations). The results presented here have been corrected accordingly, except for the sucrose gradient experiments (see below) where no corrections were applied.
$\alpha-B G T$ binding. $\alpha$-BGT was purified from the venom of Bungarus multicinctus (Ravdin and Berg, 1979). For quantitative binding studies, the diiodo species of $\left[{ }^{125} \mid\right]-\alpha$-BGT was used; it was prepared and isolated according to the method of Vogel et al. (1972) with specific activities of 2 to $3 \times 10^{17}$ $\mathrm{cpm} / \mathrm{mol}$. In some cases relative levels of toxin binding were determined using $\left.\left[{ }^{125}\right]\right]-\alpha$-BGT prepared as previously described (Lindstrom et al., 1981). $\left[{ }^{125} \mathrm{I}\right]-\alpha-B G T$ binding in detergent extracts of chick ciliary ganglia was measured by the method of Meunier et al. (1974). Reaction volumes of $0.060 \mathrm{ml}$ containing $20 \mathrm{nM}\left[{ }^{125} \mathrm{l}\right]-\alpha$-BGT and sample in HB were incubated for $1 \mathrm{hr}$ at room temperature. The reaction was terminated by diluting $0.020 \mathrm{ml}$ aliquots with $10 \mathrm{ml}$ of cold $10 \mathrm{~mm} \mathrm{NaPO}_{4}, \mathrm{pH} 7.4$, containing $50 \mathrm{mM} \mathrm{NaCl}$ (rinse buffer). Under these conditions toxin-receptor complex is precipitated while free toxin remains in solution. After $30 \mathrm{~min}$ at $4^{\circ} \mathrm{C}$, the sample was passed through a $0.22-\mu \mathrm{m}$ Millipore filter previously soaked with rinse buffer containing $2 \mathrm{mg} / \mathrm{ml}$ of BSA. The filter was then washed with two $10-\mathrm{ml}$ aliquots of cold rinse buffer and was gamma counted for radioactivity. Nonspecific binding, determined by including a 100 -fold excess of unlabeled toxin in the initial reaction mixture, was typically $5 \%$ of the total radioactivity retained by the filter and was subtracted in all cases. The efficiency of the assay was determined by binding toxin to intact ciliary ganglia, washing away free toxin, homogenizing the labeled ganglia, and determining the proportion of specific binding that was retained by the filter. This indicated an efficiency of retention of about $67 \%(\mathrm{H}$. Mullner and D. Berg, unpublished observations). The data have been corrected accordingly.

Concanavalin A binding. Binding of the MIR-like antigen to concanavalin A (con A) was tested by incubating $0.060 \mathrm{ml}$ of detergent extract (120 ciliariy ganglia/ml) with $0.01 \mathrm{ml}$ of con $\mathrm{A}-$ Sepharose $4 \mathrm{~B}$ for $30 \mathrm{~min}$ at $4^{\circ} \mathrm{C}$, centrifuging the mixture for $2 \mathrm{~min}$ in a Microfuge, and assaying the supernatant fraction for depletion of mAb 35-binding sites in the standard DEAE assay. In control experiments, to prevent specific adsorption of sites by con A, $1 \mathrm{M} \alpha$-methylmannoside, $5 \mathrm{~mm}$ EDTA, and $5 \mathrm{~mm}$ EGTA were included in the initial incubation. Elution of the MIR-like component was carried out by incubating adsorbed con $\mathrm{A}$ beads in the same additives overnight at $4^{\circ} \mathrm{C}$, recovering the supernatant fraction by centrifugation, and assaying it for the appearance of mAb 35-binding sites by the standard assay.

Sucrose gradient centrifugation. Aliquots $(0.20 \mathrm{ml})$ of detergent extract prepared from 18-day embryonic ciliary ganglia at a concentration of 200 ganglia/ml were layered onto $4.8-\mathrm{ml}$ linear gradients of 5 to $20 \%$ sucrose in HB. Centrifugation was carried out at $40,000 \mathrm{rpm}$ for $10 \mathrm{hr}$ at $4^{\circ} \mathrm{C}$ in a Beckman SW 50.1 rotor. Gradient fractions $(0.2 \mathrm{ml})$ were collected and assayed for ${ }^{125} \mathrm{I}-\mathrm{m} \wedge \mathrm{b} 35$ binding in the standard DEAE column assay. Sedimentation markers included Torpedo electric organ AChR monomer $(9$ S) and dimer (13 S) labeled with [ $\left.{ }^{125} \mathrm{I}\right]-\alpha$-BGT, catalase (11.3 S), and bacterial alkaline phosphatase $(6.1 \mathrm{~S})$ in parallel tubes as well as catalase in the same tube.

Cross-precipitation experiments, $\alpha$-Neurotoxin purified from the venom of Naja naja siamensis was conjugated to Sepharose Cl4B as previously described (Lindstrom et al., 1981) to yield $0.5 \mathrm{mg}$ of conjugated toxin/ $/ \mathrm{ml}$ of Sepharose. Reaction mixtures $(0.085 \mathrm{ml}$ liquid phase) were prepared containing the detergent extract from seven or eight ciliary ganglia, $5 \mathrm{nM}{ }^{125}$. $\mathrm{mAb} 35$ that had been passed through a DEAE cellulose column as described above, fetal calf serum at $1 \mathrm{mg}$ of protein $/ \mathrm{ml}$, and either 0.015 or $0.030 \mathrm{ml}$ of toxin-Sepharose. Before receiving the toxin-Sepharose, the reactions were incubated $1 \mathrm{hr}$ at $4^{\circ} \mathrm{C}$, and then the combined mixtures were gently agitated overnight at $4^{\circ} \mathrm{C}$. The toxin-Sepharose was collected by centrifugation in a

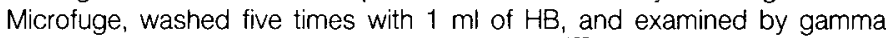
counting to determine the amount of bound ${ }^{125}$-mAb 35 (total binding). Nonspecific binding was determined by including $1.3 \mathrm{mg} / \mathrm{ml}$ of $\alpha$-BGT along with the toxin-Sepharose, and was subtracted from total binding to yield specific binding for antigen-antibody complex to the toxin-Sepharose. A small amount of labeled antibody $(\sim 0.4 \mathrm{fmol})$ adsorbed to the toxin-Sepharose even in the absence of ciliary ganglion extract and was blocked by the 1.3 $\mathrm{mg} / \mathrm{ml}$ of $\alpha$-BGT; this background adsorption was also subtracted from the total binding. In parallel experiments the ${ }^{125} \mathrm{I}-\mathrm{mAb} 35$ was omitted, and the supernatant fraction recovered after centrifuging the toxin-Sepharose was tested for remaining $\alpha$-BGT-binding sites in the standard toxin-binding assay.

To test for precipitation of toxin sites by antigen-antibody complex, a 1.1. $\mathrm{ml}$ detergent extract prepared with 83 ciliary ganglia from 20 -day-old chick embryos was incubated in $\left.10 \mathrm{nM}\left[{ }^{125}\right]\right]-\alpha$-BGT for $2 \mathrm{hr}$ at $4^{\circ} \mathrm{C}$. The extract was then diluted 4-fold, divided into aliquots, and incubated overnight at $4^{\circ} \mathrm{C}$ in duplicate with rat anti-Torpedo antibodies (26 nM), mAb 35 (110 nM), or mAb 203 (178 nM) together with carrier normal rat serum. These concentrations represented an 11-, 58-, and 45- times excess, respectively, of antibody over antigen sites in the extract. Goat anti-rat IgG sufficient to precipitate the rat antibody was then added, and after $4 \mathrm{hr}$ at $4^{\circ} \mathrm{C}$, the precipitate was collected by centrifugation, rinsed two times, and counted for gamma radiation. Substitution of normal rat serum for anti-receptor antibody was 
used to determine nonspecific binding and/or trapping of radioactivity in the precipitate. Aliquots of the original undiluted extract were incubated in parallel with $10 \mathrm{nM}\left[{ }^{225}\right]-\alpha$-BGT in the absence of antibody to assay for total $\alpha$-BGT binding.

Materials. Torpedo AChR was purified from electric organ tissue and stored as previously described (Lindstrom et al., 1981). Protein was determined by the Bio-Rad protein assay. Bungarus multicinctus venom was purchased from Miami Serpentarium. con A coupled to Sepharose 4B, CN Br-Sepharose 4B beads, $\alpha$-methyl-mannoside, leupeptin, pepstatin A, catalase, and bacterial alkaline phosphatase were purchased from Sigma Chemical Co. Sepharose Cl4B was purchased from Pharmacia.

\section{Results}

mAb 35 binding. Binding of ${ }^{125} \mathrm{H}$-mAb 35 to the MIR-like component in chick ciliary ganglion extracts was measured by using a DEAE cellulose column to adsorb the antigen-antibody complex while allowing free antibody to pass through. Under standard conditions, formation of the antigen-antibody complex was complete in $15 \mathrm{~min}$, and the amount of complex formed was directly proportional to the amount of extract (Fig. 1). Near saturation of antigen was achieved at about $5 \mathrm{~nm}{ }^{125} \mathrm{I}-\mathrm{mAb} 35$ (Fig. 2). Scatchard analysis of the data from three separate experiments revealed a single class of high affinity mAb 35-binding sites with an apparent equilibrium dissociation constant, $K_{D}$, of $0.85 \pm 0.03 \mathrm{nM}$. For 17 - to 18-day-old chick embryos, $7.4 \pm 0.7(n=3) \mathrm{fmol}$ of antibody binding component were obtained per ciliary ganglion.

That the binding of ${ }^{125} \mathrm{I}$-mAb 35 depends on its specificity can be demonstrated by competition experiments with other antibodies.

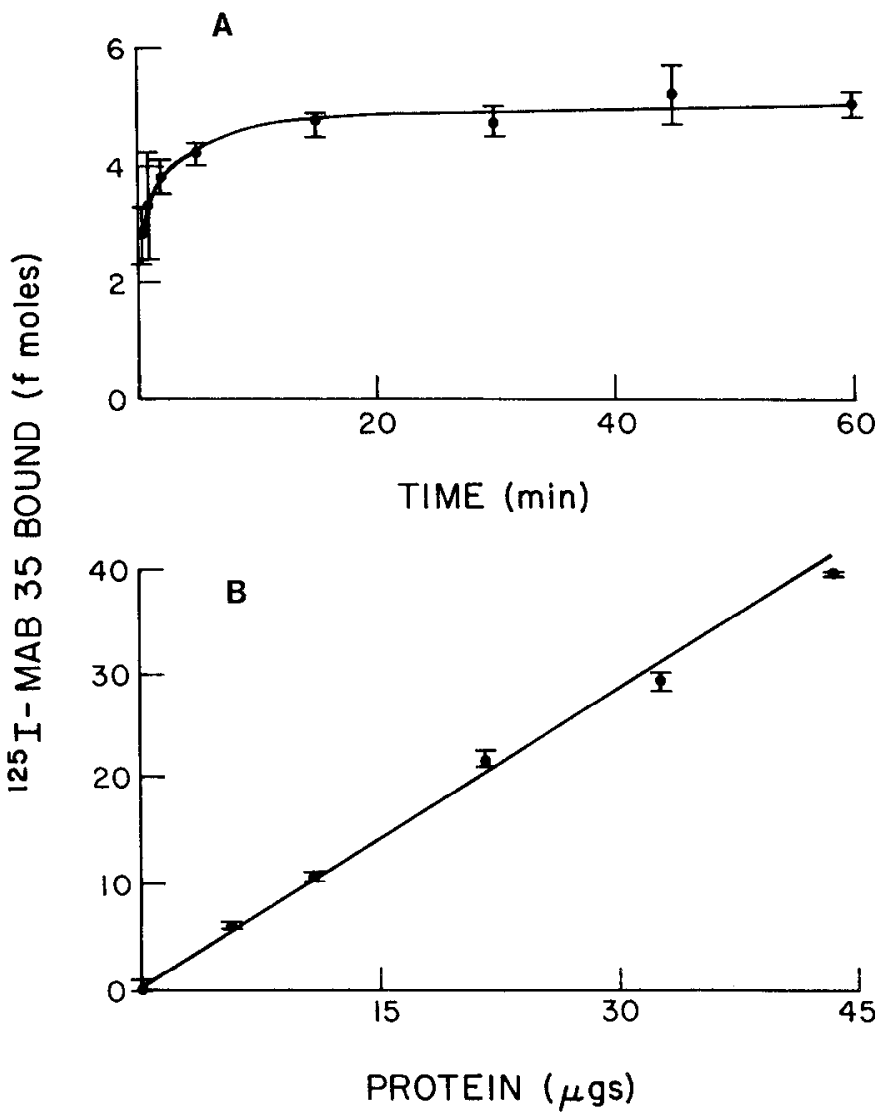

Figure 1. Time dependence and linearity with protein for mAb 35 binding. Specific binding of $\mathrm{mAb} 35$ to the MIR-like determinant was determined in detergent extracts of ciliary ganglia. $A$, At the indicated times, samples were taken from the standard reaction mixture for analysis. $B$. The concentration of ganglionic protein was adjusted in the reaction mixtures to yield the indicated amount of protein per standard sample analyzed. Each point represents the mean \pm SEM of three determinations. Similar results were obtained in two other experiments.

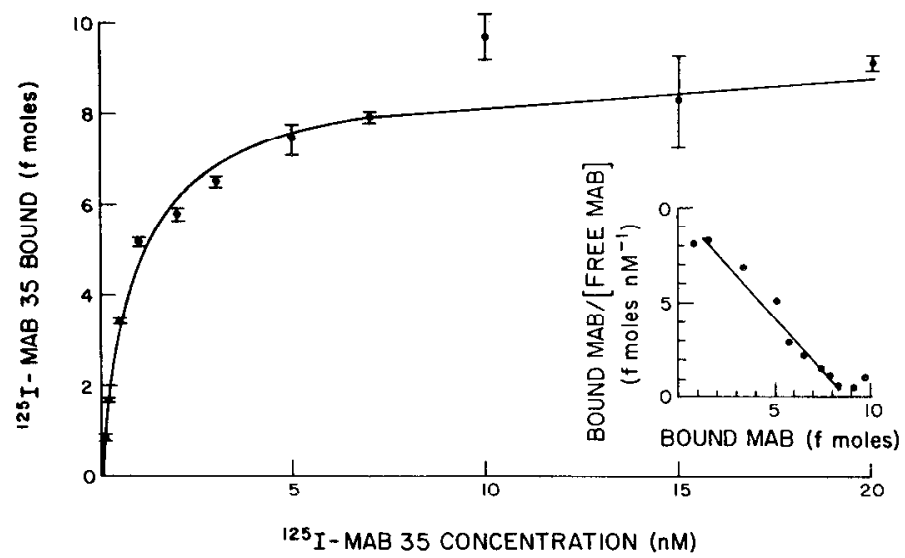

Figure 2. Concentration dependence of mAb 35 binding. Reaction mix tures containing the indicated concentrations of ${ }^{125} 1$-mAb 35 were assayed for antibody binding under standard conditions. Each point represents the mean \pm SEM of three determinations. Scatchard analysis of the data (inset) indicates $8.6 \mathrm{fmol}$ of antibody binding sites/18-day embryonic ganglion with an apparent equilibrium dissociation constant, $K_{D}$, of $0.9 \mathrm{nM}$

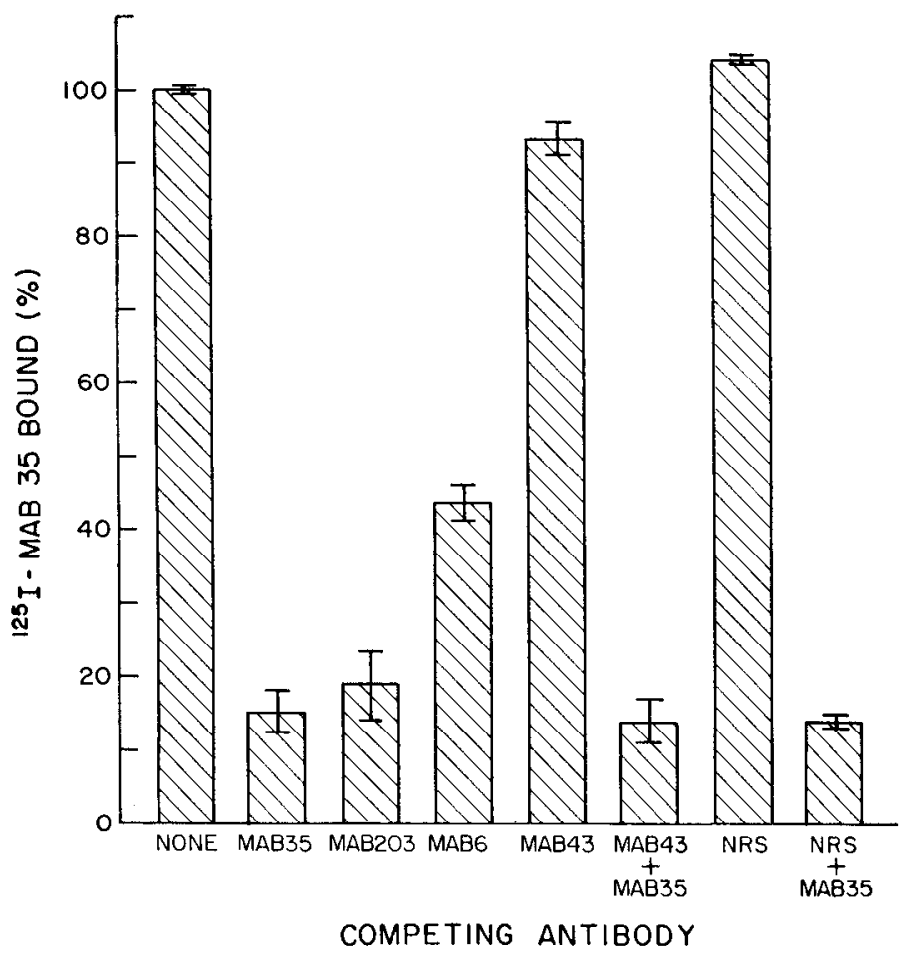

Figure 3. Specificity of antibody binding. The indicated antibodies were incubated at $0.30 \mu \mathrm{M}$ along with ${ }^{125} \mathrm{ImAb} 35$ in the initial reaction mixture and binding of ${ }^{125} \mathrm{~F}-\mathrm{mAb} 35$ to antigen was then determined. Each value represents the mean \pm SEM of three experiments. None: no competing antibody; MAB35, 203, 6, and 43: mAbs 35, 203, 6, and 43, respectively; NRS: normal rat serum.

Anti-MIR mAbs 6 and 203 blocked ${ }^{125} 1$-mAb 35 binding nearly as efficiently as did mAb 35 . No blockade of ${ }^{125}$-mAb 35 binding was seen with mAb 43, a mAb of the same subclass as mAb 35 but of different specificity, or with normal rat serum at a comparable dilution of IgG. Lack of blockade in these cases did not reflect problems with the competition assay since mAb 35 was still able to prevent ${ }^{125} \mathrm{I}-\mathrm{mAb} 35$ binding even in the presence of mAb 43 or normal rat serum (Fig. 3).

Tissue distribution. The tissue distribution of the MIR-like component is consistent with that expected for a ganglionic AChR. High levels of ${ }^{125}$-mAb 35 binding were obtained with extracts prepared 
from ciliary ganglia and sympathetic ganglia which are known to contain nicotinic AChRs. Little if any specific binding was detected in extracts of dorsal root ganglia, retina, spinal cord, heart, or liver (Fig. 4).

Physical properties. The MIR-like antigen in the chick ciliary ganglion is an integral membrane component. All of the antibody binding sites (101 $\pm 1 \%, n=3$ ) were associated with membrane fragments in the absence of detergent, and most of the sites $(80 \pm$ $9 \%, n=5$ ) were retained in the membrane after extraction with $1 \mathrm{M}$ $\mathrm{NaCl}$.

Moreover, the component is glycosylated, as expected for an integral membrane protein. con A conjugated to Sepharose beads was tested for its ability to deplete the MIR-like component from extracts. Nearly all of the MIR-like component was removed from solution by the con A-Sepharose (Table I). Adsorption of the antigen was completely blocked by high concentrations of the con A ligand
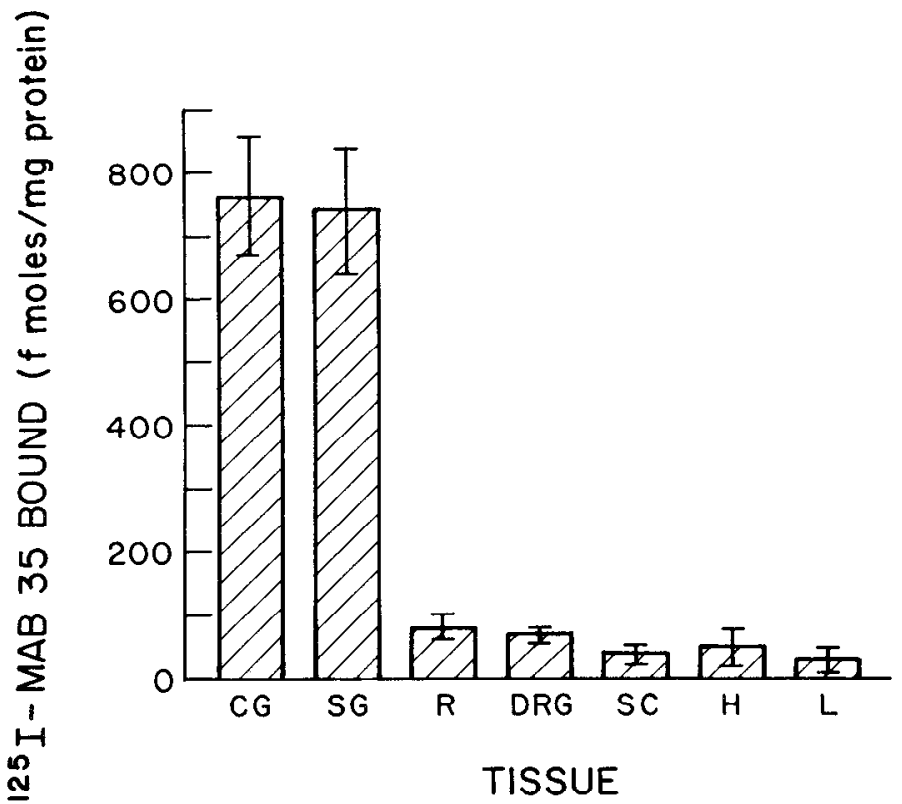

TISSUE

Figure 4. Tissue distribution of the MIR-like component. Tissue extracts were adjusted with HB to yield similar concentrations of protein and then were assayed for ${ }^{125} \mathrm{I}-\mathrm{mAb} 35$ binding in the standard assay. Results represent the mean $\pm S E$ for three to eight experiments for each tissue. $C G$, ciliary ganglia; $S G$, sympathetic ganglia; $R$, retina; $D R G$, dorsal root ganglia; SC, spinal cord; $H$, heart; $L$, liver.

\section{TABLE}

\section{Binding of the MIR-like component to con A-Sepharose}

Ciliary ganglion extracts were incubated under various conditions, centrifuged, and assayed for ${ }^{125}$-mAb 35 -binding sites remaining in the supernatant fraction, as follows: None, no additives to the extract; con A-Seph, addition of con A-Sepharose to the extract; con A-Seph + blockers, addition of con A-Sepharose to the extract in the presence of $1 \mathrm{M} \alpha$-methyl-mannoside, 5 $\mathrm{mM}$ EGTA, and $5 \mathrm{~mm}$ EDTA; Elution of adsorbed con A-Seph, addition of con A-Seph to the extract, followed by centrifugation to collect the adsorbed con A-Sepharose, incubation of the collected material in the blockers, recentrifugation to remove the con A-Sepharose, and assay of the recovered supernatant fraction for eluted antibody-binding sites.

\begin{tabular}{lcc}
\hline \multirow{2}{*}{ Treatment of Extract } & \multicolumn{2}{c}{$\begin{array}{c}\text { Proportion of mAb 35 Sites Recovered } \\
\text { in Supernatant Fraction }\end{array}$} \\
\cline { 2 - 3 } & Experiment 1 (\%) & Experiment 2 (\%) \\
\hline None & $100 \pm 3$ & $100 \pm 4$ \\
Con A-Seph & $1 \pm 3$ & $10 \pm 9$ \\
Con A-Seph + blockers & $103 \pm 1$ & $88 \pm 6$ \\
Elution of adsorbed con & $41 \pm 1$ & $33 \pm 6$ \\
A-Seph & & \\
\hline
\end{tabular}

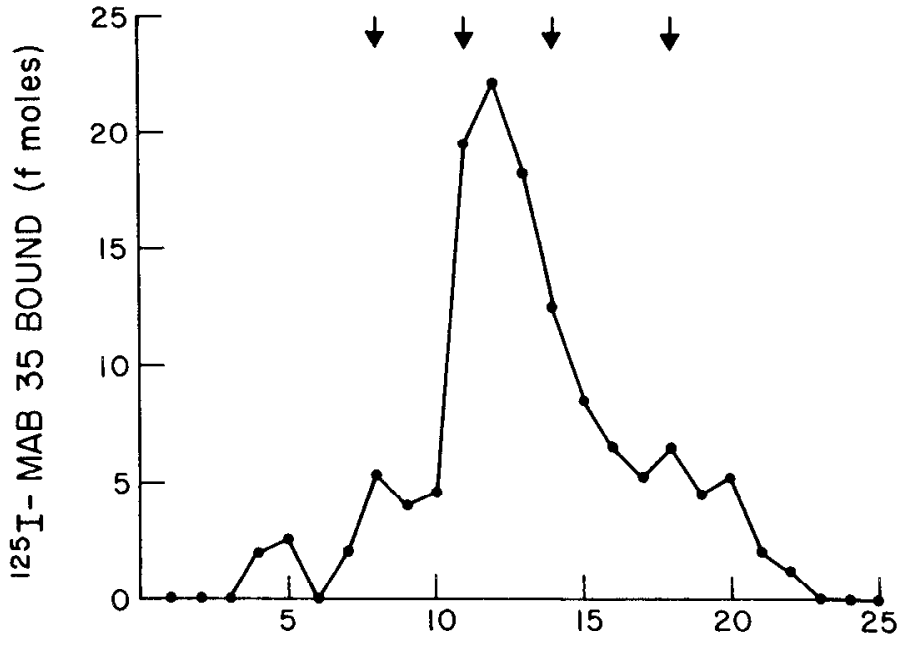

\section{FRACTION NUMBER}

Figure 5. Sucrose gradient sedimentation of the M:R-like component in ciliary ganglion extracts. A detergent extract of 18-day embryonic ciliary ganglia was centrifuged through a sucrose gradient; fractions were collected and assayed for ${ }^{125} \mathrm{I}-\mathrm{mAb} 35$ binding in duplicate. Total recovery of MIR-like component (determined by assaying aliquots of the starting material in parallel) from the gradient was $79 \%$. The arrows indicate the position from left to right of sedimentation markers: Torpedo electric organ AChR dimer (13 S), catalase (11.3 S), Torpedo AChR monomer (9 S), and bacterial alkaline phosphatase $(6.1 \mathrm{~S})$. Similar results were obtained in three other experiments.

$\alpha$-methyl-mannoside in the presence of divalent cation chelators. Partial elution of the component after adsorption to the con ASepharose was achieved by treating the adsorbed material with $\alpha$ methyl-mannoside and the chelators (Table I).

The sedimentation properties of the detergent-soluble material were examined by ultracentrifugation of ganglion extract through a sucrose gradient and assaying the recovered fractions for ${ }^{125} \mathrm{l}-\mathrm{mAb}$ 35 binding in the standard assay. About two-thirds of the recovered MIR-like component migrated as a single species with a sedimentation coefficient of about $10 \mathrm{~S}$ (Fig. 5).

Co-precipitation. Ultrastructural studies have shown that most of the mAb 35-binding sites found on the surface of ciliary ganglion ncurons in intact ganglia are different from $\alpha$-BGT-binding sites on the neurons since the antibody-binding sites occur largely in synaptic membrane, whereas the toxin sites are preferentially associated with dendritic membrane and appear to be excluded from synaptic membrane (Jacob and Berg, 1983; Jacob, et al., 1984). However, some antibody binding was also detected on dendritic membranes where toxin binding was normally prominent (Jacob et al., 1984). To determine whether the MIR-like component detected in ganglion extracts was distinct from the $\alpha$-BGT binding component, co-precipitation experiments were devised in which $\alpha$-neurotoxin from Naja naja siamensis venom was conjugated to Sepharose and the conjugate was used to adsorb the $\alpha$-BGT binding component. If the $\mathrm{mAb} 35$-binding site were associated with the same molecule as the toxin site, ${ }^{125} \mathrm{I}-\mathrm{mAb} 35$ bound to antigen in the extract should have co-adsorbed to the Sepharose and should have been removed from the extract. The standard binding assays indicated at the outset that extracts prepared from 17- and 18-day embryonic ganglia contain about 8 times as many $\alpha$-BGT-binding sites as MIR-like component (data not shown). Under conditions in which $96 \%$ of the toxin sites were precipitated by the toxin-Sepharose, about $2 \%$ of the antibodybinding sites appeared to co-precipitate; i.e., the amount of ${ }^{125} \mathrm{I}-\mathrm{mAb}$ 35 specifically associated with the toxin-Sepharose was equivalent on a molar basis to $2 \%$ of the number of mAb 35-binding sites present in the extract (Table II). Lack of co-precipitation here cannot 
TABLE ॥

Lack of co-precipitation for the MIR-like component and $\alpha$-BGT-binding sites

Ciliary ganglion extracts were incubated with ${ }^{125}$-mAb 35 to tabel the MIRlike component and then were mixed with $\alpha$-neurotoxin conjugated to Sepharose (Toxin-Seph) to adsorb the $\alpha$-BGT-binding component. The amount of labeled antibody specifically associated with the Sepharose conjugate in the presence of extract (Adsorbed ${ }^{125} \mathrm{I}-\mathrm{mAb} 35$ ) was then determined and taken to represent the number of MIR-like molecules coadsorbed with the toxin-binding component (as an upper limit) and is expressed as a percentage of the total mAb sites. The proportion of $\alpha$-BGT sites adsorbed to the conjugate was determined as described in Materials and Methods. The values represent the mean \pm SEM of three determinations in each experiment. Similar results were obtained in two additional experiments using an $\alpha$-BGT-Sepharose conjugate.

\begin{tabular}{cccccc}
\hline Experiment & Toxin-Seph & $\begin{array}{c}\text { Total mAb } \\
35 \text { Sites }\end{array}$ & $\begin{array}{c}\text { Adsorbed } \\
\text { 125/-mAb 35 }\end{array}$ & $\begin{array}{c}\text { Proportion of Sites } \\
\text { Adsorbed to Toxin-Seph }\end{array}$ \\
\hline & $m /$ & \multicolumn{2}{c}{ mAb 35 Sites $\alpha$-BGT Sites } \\
\hline 1 & 0.015 & $49.1 \pm 4.2$ & $0.78 \pm 0.10$ & $1.5 \%$ & $96 \%$ \\
2 & 0.030 & $38.1 \pm 3.3$ & $0.90 \pm 0.30$ & $2.4 \%$ & $96 \%$ \\
\hline
\end{tabular}
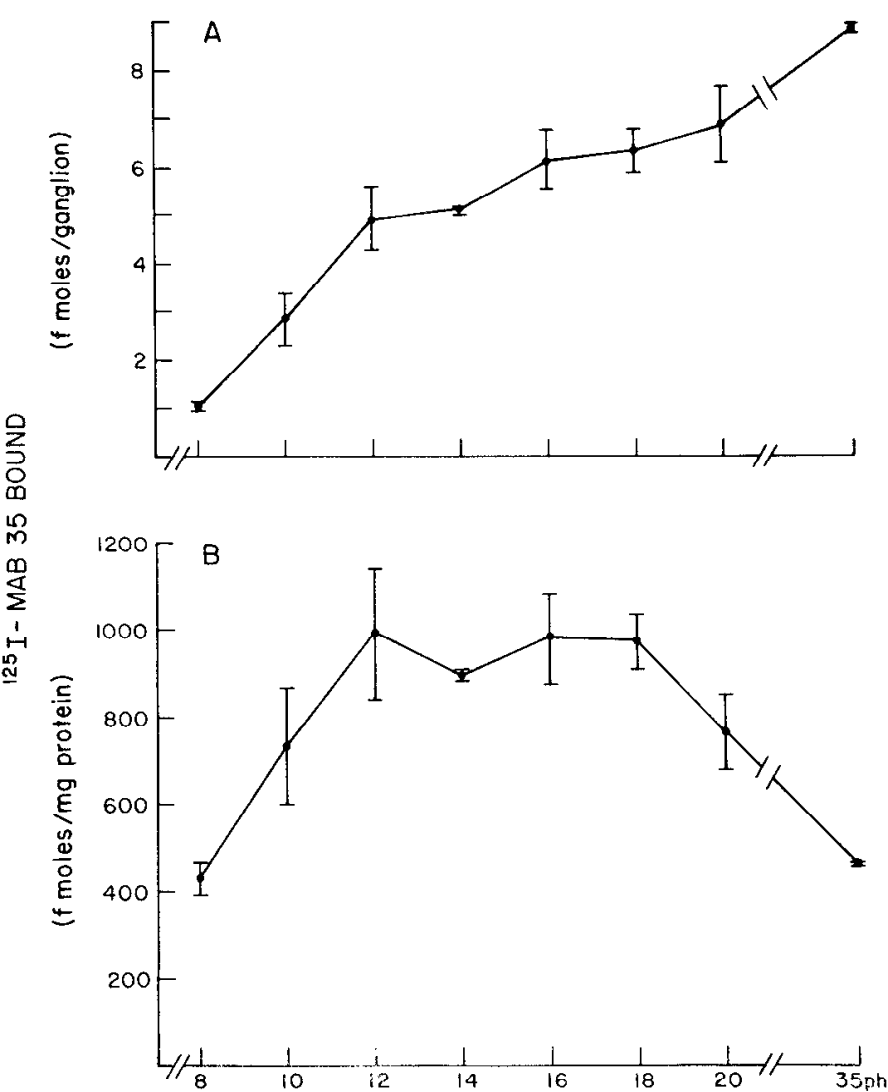

EMBRYONIC AGE (days)

Figure 6. Development of the MIR-like component in ciliary ganglia. Ciliary ganglia were dissected from chick embryos at the indicated times and from 5 -week-old chicks (35ph), homogenized in $\mathrm{HB}$, and assayed for ${ }^{125} \mathrm{k}$-mAb 35 binding and protein. $A$, Antibody binding per ganglion. $B$, Antibody binding per milligram of ganglionic protein. Each point represents the mean \pm SE of three determinations, except for 35 days post-hatching $(p h)$ where duplicate determinations were performed

be ascribed to direct competition between the toxin and mAb 35 binding to the same site. Control experiments indicated that high concentrations of $\alpha$-BGI were unable to reduce the amount of ${ }^{125}$ mAb 35 binding in ganglion extracts (data not shown).
As an alternative approach to the same question, antibodies were used to precipitate the MIR-like antigen from ciliary ganglion extracts while monitoring the distribution of toxin sites during the procedure. Fxtracts were first incubated with ${ }^{125} \mathrm{I}-\alpha$-BGT to label the toxin sites. Rat anti-Torpedo AChR antibodies, mAb 35, or mAb 203 were then added to bind the MIR-like antigen, and goat anti-rat IgG was added to precipitate the antigen-antibody complex. In each case the amount of precipitated toxin did not exceed $2 \%$ of the number of toxin sites known to be present in the extract. In repeat experiments with antiTorpedo AChR antibodies and with $\mathrm{mAb} 35$, the precipitated toxin represented less than $4 \%$ of the sites in each case.

Development. The amounl of MR-like component in the ciliary ganglion is developmentally regulated. A 6-fold increase occurred in the amount of component per ganglion between embryonic days 8 and 16 (Fig. 6A). Little additional increase was seen up to 5 weeks post-hatch. When normalized for ganglionic protein, the specific activity of the MIR-like component reached a maximum at day 12 in the embryo and decreased markedly during the late embryonic and post-hatch periods (Fig. 6B).

\section{Discussion}

The MIR-like component in the chick ciliary ganglion has several properties expected for a ganglionic nicotinic AChR. It shares a determinant with nicotinic AChRs from muscle and electric organ. It is an integral membrane component that sediments in detergent extracts primarily as a species of $10 \mathrm{~S}$, a value close to that observed for AChR monomers from skeletal muscle and electric organ (Changeux et al., 1984). The component binds to con $A$, and con $A$ is known to block AChR function on the neurons (Messing et al., 1984), implying that con $A$ interacts with the functional receptor. Of the tissues tested here, the component is restricted to those known to contain ganglionic AChRs. The greatest increase in specific activity of the MIR-like component in the ganglion occurs between embryonic days 8 and 12 when synapses are being consolidated in the ganglion (Landmesser and Pilar, 1972, 1978). Previous studies on the distribution of surface components in the ganglion have demonstrated that the MIR-like component on the neuronal surface is located predominantly in the synaptic membrane (Jacob et al., 1984).

Several of these points deserve additional comment. With respect to tissue distribution, relatively little mAb 35 binding was detected in extracts of chick retina although the tissue is known to contain nicotinic AChRs (Betz, 1981). Either the retina receptors fail to bind $\mathrm{mAb} 35$ or the heterogeneily of the lissue results in a specific activity for receptors (AChR per milligram of protein) too low for detection in the present assay. Anti-MIR mAb binding has previously been reported for the lateral spiriform nucleus of chick brain (Lindstrom et al., 1983. Swanson et al., 1983). Although functional AChRs have yet to be demonstrated in the nucleus, cross-reactivity was reported with mAbs specific for each of the subunits in AChR from muscle and electric organ. It is possible that the nucleus has ganglionic type AChRs.

The ultrastructural studies demonstrating a predominantly synaptic location for the MIR-like component were confined to surface sites (Jacob et al., 1984). Frozen sections cut from the lateral spiriform nucleus (Swanson et al., 1983) and from the ciliary ganglion (M. Jacob and D. Berg, unpublished studies) indicate that substantial amounts of the MIR-like component appear to be intracellular. Studies in cell culture demonstrate that nearly two-thirds of the MIR-like component associated with ciliary ganglion neurons is intracellular (J. Stollberg, unpublished observations). If the same is true of the ganglion, much of the material examined here could represent an integral membrane component associated with intracellular membranes. Although this seems surprising for a membrane receptor, it should be noted that both muscle AChRs and nerve growth factor receptors on cell lines sometimes have predominantly intracellular localizations (Olson et al., 1983; Ross et al., 1984).

Ciliary ganglia have many more $\alpha$-BGT sites than do MIR-like 
components. Differences in the surface distribution of $\alpha$-BGT and $\mathrm{mAb} 35$ binding on the neurons indicated that the surface sites are separate membrane molecules (Jacob and Berg, 1983; Jacob et al., 1984). The cross-precipitation experiments carried out here on total sites in ganglion extracts support a similar conclusion: $98 \%$ of the $\mathrm{mAb} 35$-binding sites failed to precipitate with toxin sites and vice versa, confirming that they represent distinct molecules.

The MIR-like component in ciliary ganglion extracts has a number of properties expected for a ganglionic AChR. None of the features described, however, can be considered definitive. The MIR determinant is apparently not directly involved in the receptor active site since cholinergic ligands do not inhibit anti-MIR mAb binding, and the mAbs do not block AChR function either on muscle or on ciliary ganglion neurons (data not shown). Accordingly, additional studies will be needed to demonstrate whether a positive correlation exists between AChR function and the number of anti-MIR mAb-binding sites on the neurons.

\section{References}

Ascher, P., W. A. Large, and H. P. Rang (1979) Studies on the mechanism of action of acetylcholine antagonists on rat parasympathetic ganglion cells. J. Physiol. (Lond.) 295: 139-170.

Betz, H. (1981) Characterization of the alpha-bungarotoxin receptor in chick embryo retina. Eur. J. Biochem. 117: 131-139.

Block, G. A., and R. B. Billiar (1979) Immunologic similarities between the hypothalamic alpha-bungarotoxin receptor and the Torpedo californica nicotinic cholinergic receptor. Brain Res. 178: 381-387.

Brown, D. A., and L. Fumagalli (1977) Dissociation of alpha-bungarotoxin binding and receptor block in the rat superior cervical ganglion. Brain Res. 129: 165-168.

Bursztajn, S., and M. D. Gershon (1977) Discrimination between nicotinic receptors in vertebrate ganglia and skeletal muscle by alpha-bungarotoxin and cobra venoms. J. Physiol. (Lond.) 269: 17-31.

Carbonetto, S. T., D. M. Fambrough, and K. J. Muller (1978) Non-equivalence of alpha-bungarotoxin receptors and acetylcholine receptors in chick sympathetic neurons. Proc. Natl. Acad. Sci. U. S. A. 75: 1016-1020.

Changeux, J. -P., A. Devillers-Thiery, and P. Chemouilli (1984) Acetylcholine receptor: An allosteric protein. Science 225: 1335-1345.

Chiappinelli, V. A., J. B. Cohen, and R. E. Zigmond (1981) The effects of alpha- and beta-neurotoxins from the venom of various snakes on transmission on autonomic ganglia. Brain Res. 211: 107-126.

Duggan, A. W., J. G. Hall, and C. Y. Lee (1976) Alpha-bungarotoxin, cobra neurotoxin and excitation of Renshaw cells by acetylcholine. Brain Res. 107: $166-170$.

Jacob, M. H., and D. K. Berg (1983) The ultrastructural localization of $\alpha$ bungarotoxin binding sites in relation to synapses on chick ciliary ganglion neurons. J. Neurosci. 3: 260-271.

Jacob, M. H., D. K. Berg, and J. M. Lindstrom (1984) Shared antigenic determinant between the Electrophorus acetylcholine receptor and a synaptic component on chicken ciliary ganglion neurons. Proc. Natl. Acad. Sci. U. S. A. 81: 3223-3227

Ko, C. P., H. Burton, and R. P. Bunge (1976) Synaptic transmission between rat spinal cord explants and dissociated superior cervical ganglion neurons in tissue culture. Brain Res. 117: 437-460.

Kouvelas, E. D., M. A. Dichter, and L. A. Greene (1978) Chick sympathetic neurons develop receptors for alpha-bungarotoxin in vitro, but the toxin does not block nicotinic receptors. Brain Res. 154: 83-93.

Landmesser, L., and G. Pilar (1972) The onset and development of transmission in the chick ciliary ganglion. J. Physiol. (Lond.) 222: 691 -713.

Landmesser, L., and G. Pilar (1978) Interactions between neurons and their targets during in vivo synaptogenesis. Fed. Proc. 37: 2016-2022.

Lindstrom, J., B. Einarson, and S. Tzartos (1981) Production and assay of antibodies to acetylcholine receptors. Methods Enzymol. 74: 432-459.

Lindstrom, J., S. Tzartos, W. Gullick, S. Hochschwender, L. Swanson, P Sargent, M. Jacob, and M. Montal (1983) Use of monoclonal antibodies to study acetylcholine receptors from electric organs, muscle, and brain and the autoimmune response to receptor in myasthenia gravis. Cold Spring Harbor Symp. Quant. Biol. 48: 89-99.

Marshall, L. M. (1981) Synaptic localization of alpha-bungarotoxin binding which blocks nicotinic transmission at frog sympathetic neurons. Proc. Natl. Acad. Sci. U. S. A. 78: 1948-1952.

Martin, A. R., and G. Pilar (1963a) Dual mode of synaptic transmission in the avian ciliary ganglion. J. Physiol. (Lond.) 168: 443-463.

Martin, A. R., and G. Pilar (1963b) Transmission through the ciliary ganglion of the chick. J. Physiol. (Lond.) 168: 464-475.
Mehraban, F., J. T. Kemshead, and J. O. Dolly (1984) Properties of monoclonal antibodies to nicotinic acetylcholine receptor from chick muscle. Eur. J. Biochem. 138: 53-61.

Messing, A., B. Bizzini, and N. K. Gonatas (1984) Concanavalin A inhibits nicotinic acetylcholine receptor function in cultured chick ciliary ganglion neurons. Brain Res. 303: 241-249.

Meunier, J. C., R. Sealock, R. Olsen, and J. P. Changeux (1974) Purification and properties of the cholinergic receptor protein from Electrophorus electricus electric tissue. Eur. J. Biochem. 45: 371-394.

Mills, A., and S. Wonnacott (1984) Antibodies to nicotinic acetylcholine receptors used to probe the structural and functional relationships between brain alpha-bungarotoxin binding sites and nicotinic receptors. Neurochem. Int 6: 249-257

Mitsuka, M., and H. Hatanaka (1983) Selective loss of acetylcholine sensitivity in a nerve cell line cultured in hormone-supplemented serum-free medium. J. Neurosci. 3: $1785-1790$.

Norman, R. I., F. Mehraban, E. A. Barnard, and J. O. Dolly (1982) Nicotinic acetylcholine receptor from chick optic lobe. Proc. Natl. Acad. Sci. U. S. A. 79 : $1321-1325$.

Nurse, C. A., and P. H. O'Lague (1975) Formation of cholinergic synapses between dissociated sympathetic neurons and skeletal myotubes of the rat in cell culture. Proc. Natl. Acad. Sci. U. S. A. 72: 1955-1959.

Olson, E. N., L. Glaser, J. P. Merlie, R. Sebanne, and J. Lindstrom (1983) Regulation of surface expression of acetylcholine receptors in response to serum and cell growth in the $\mathrm{BC}_{3} \mathrm{H} 1$ muscle cell line. J. Biol. Chem. 258: 13946-13953.

Oswald, R. E., and J. A. Freeman (1981) Alpha-bungarotoxin binding and central nervous system nicotinic acetylcholine receptors. Neuroscience 6 : 1-14.

Patrick, J., and W. B. Stallcup (1977a) Alpha-bungarotoxin binding and cholinergic receptor function on a rat sympathetic nerve line. J. Biol. Chem. 252: 8629-8633.

Patrick, J., and W. B. Stallcup (1977b) Immunological distinction between acetylcholine receptor and the alpha-bungarotoxin binding component on sympathetic neurons. Proc. Natl. Acad Sci. U. S. A. 74: 4689-4692.

Ravdin, P. M., and D. K. Berg (1979) Inhibition of neuronal acetylcholine sensitivity by alpha-toxins from Bungarus multicinctus venom. Proc. Natl. Acad. Sci. U. S. A. 76: 2072-2076.

Ravdin, P. M., R. M. Nitkin, and D. K. Berg (1981) Internalization of $\alpha$ bungarotoxin on neurons induced by a neurotoxin that blocks neuronal acetylcholine sensitivity. J. Neurosci. 1: 849-861.

Ross, A. H., P. Grob, M. Bothwell, D. E. Elder, C. S. Ernst, N. Marano, B. F. D. Ghrist, C. C. Slemp, M. Herlyn, B. Atkinson and H. Koprowski (1984) Characterization of nerve growth factor receptor in neural crest tumors using monoclonal antibodies. Proc. Natl. Acad. Sci. U. S. A. 81: 66816685.

Smith, M. A., J. F. Margiotta, and D. K. Berg (1983) Differential regulation of acetylcholine sensitivity and $\alpha$-bungarotoxin-binding sites on ciliary ganglion neurons in cell culture. J. Neurosci. 3: 2395-2402.

Smith, M. A., J. Stollberg, D. K. Berg, and J. M. Lindstrom (1984) Characterization of a component in chick ciliary ganglia that crossreacts with monoclonal antibodies to acetylcholine receptor from muscle and electric organ. Soc. Neurosci. Abstr. 10: 936.

Swanson, L. W., J. Lindstrom, S. Tzartos, L. C. Schmued, D. D. M. O'Leary, and W. M. Cowan (1983) Immunohistochemical localization of monoclonal antibodies to the nicotinic acetylcholine receptor in chick midbrain. Proc. Natl. Acad. Sci. U. S. A. 80: 4532-4536.

Syapin, P. J., P. M. Salvaterra, and J. K. Engelhardt (1982) Neuronal-like features of TE671 cells: Presence of a functional nicotinic cholinergic receptor. Brain Res. 231: 365-377.

Tzartos, S., D. E. Rand, B. L. Einarson, and J. M. Lindstrom (1981) Mapping of surface structures of Electrophorus acetylcholine receptor using monoclonal antibodies. J. Biol. Chem. 256: 8635-8645.

TLartos, S., L. Langeberg, S. Hochisctiwender, and J. Lindsirom (1983) Demonstration of a main immunogenic region on acetylcholine receptors from human muscle using monoclonal antibodies to human receptor. FEBS Lett. 158: 116-118.

Tzartos, S. J., and J. M. Lindstrom (1980) Monoclonal antibodies used to probe acetylcholine receptor structure: Localization of the main immuno. genic region and detection of similarities between subunits. Proc. Natl. Acad. Sci. U. S. A. 77: 755-759.

Vogel, A., A. J. Sytkowski, and M. W. Nirenberg (1972) Acetylcholine receptors of muscle grown in vitro. Proc. Natl. Acad. Sci. U. S. A. 69: 3180-3184

Wonnacott, S., R. Harrison, and G. Lunt (1982) Immunological cross-reactivity between the alpha-bungarotoxin-binding component from rat brain and nicotinic acetylcholine receptor. J. Neuroimmunol. 3: 1-13. 